\title{
Desejo por filhos entre mulheres de alta escolaridade: conflitos, mudanças e permanências
}

\author{
Andréa Branco Simão* \\ Raquel Zanatta Coutinho* \\ Gilvan Ramalho Guedes ${ }^{\star \star \star}$
}

\begin{abstract}
Este trabalho analisa as percepções e os significados da maternidade para um grupo de mulheres de alta escolaridade, casadas ou em união consensual, com no máximo um filho, residentes em um município mineiro de porte médio. Os dados provêm de 16 entrevistas semiestruturadas, realizadas em 2018 no município de Governador Valadares, MG. Os resultados indicam que, embora a maternidade seja um acontecimento desejado e valorizado, a decisão dessas mulheres não é isenta de dúvidas em relação às dificuldades para conciliar um filho com o desejo de liberdade e crescimento profissional. Essas dúvidas decorrem do fato de a maternidade ainda ter um lugar de destaque na vida das mulheres, mesmo entre um grupo de vanguarda, e se tornar mãe permanece tendo um efeito expressivo em suas vidas. Os conflitos gerados pela concomitância entre a permanência do desejo relacionado à maternidade e a emergência de novos projetos individuais apresentados às mulheres desafiam a lógica tradicional que relaciona escolaridade e projetos reprodutivos.
\end{abstract}

Palavras-chave: Maternidade. Mudanças e permanências. Desejo por filhos. Alta escolaridade. Métodos qualitativos.

\footnotetext{
* Centro de Desenvolvimento e Planejamento Regional, Universidade Federal de Minas Gerais (Cedeplar/UFMG), Belo Horizonte-MG, Brasil (deia@cedeplar.ufmg.br; http://orcid.org/0000-0003-2514-0301).

** Centro de Desenvolvimento e Planejamento Regional, Universidade Federal de Minas Gerais (Cedeplar/UFMG), Belo Horizonte-MG, Brasil (quelzanatta@cedeplar.ufmg.br; http://orcid.org/0000-0002-2841-1480).

*** Centro de Desenvolvimento e Planejamento Regional, Universidade Federal de Minas Gerais (Cedeplar/UFMG), Belo Horizonte-MG, Brasil (gilvan@epopea.com.br; http://orcid.org/0000-0001-8231-238X).
} 


\section{Introdução}

Nas últimas duas décadas, a taxa de fecundidade total no Brasil passou de 2,4 filhos para pouco menos de 1,8 filho por mulher (IBGE, 2017). Os estudos que explicam a queda da fecundidade e o anseio por famílias menores no país têm explorado três pontos-chave: o impacto das transformações socioeconômicas e culturais sobre o desejo por filhos; a capacidade de conciliá-los com a dinâmica da vida moderna; e, não menos importante, as questões atinentes à capacidade contraceptiva da mulher para realizar o seu planejamento reprodutivo (CAMARANO et al., 1999; GUEDES, 2008; ALVES; CAVENAGHI, 2009; MIRANDA-RIBEIRO; POTTER, 2010; CARVALHO; VERONA, 2014; ARAUJO et al., 2018; BERNARDI et al., 2018; BORGES, 2018; GAMA et al., 2018; GUIGINSKI; WAJNMAN, 2019; MA; PIAO, 2020). Relatos de mulheres que têm menos filhos do que gostariam (CARVALHO et al., 2016), ou que não veem em sua trajetória de vida a possibilidade de encaixar a maternidade, são cada vez mais comuns (TRINDADE et al., 2016). De acordo com Leocádio (2018), enquanto 9,0\% das mulheres pertencentes à coorte de nascimento de 1942-1946 terminaram o período reprodutivo sem filhos, entre as que nasceram de 1966 a 1970 esse percentual atingiu $13,5 \%$. Tal diferença observada entre as coortes de nascimento representa um hiato de quase $50 \%$. Análises recentes, utilizando métodos indiretos com dados censitários, mostram que o percentual de mulheres sem filho ao final do período reprodutivo deve continuar crescendo nos próximos anos no Brasil em função do adiamento do primeiro filho (MIRANDA-RIBEIRO et al., 2019).

Dentre as mudanças culturais mais expressivas para a configuração desse novo cenário reprodutivo, estão as transformações ideacionais em relação ao significado da maternidade (MIRANDA-RIBEIRO; POTTER, 2010), a secularização da sociedade (ADSERÀ, 2015) e a diferenciação da influência da religião, tanto sobre o comportamento quanto sobre as decisões reprodutivas (CARVALHO; VERONA, 2014; BORGES, 2018). 0 estabelecimento de relações de gênero mais igualitárias também passou a ser visto como um fator relevante, ao possibilitar às mulheres maior liberdade e independência para realização de sonhos em outras esferas de suas vidas (SCAVONE, 2001; GUEDES, 2008; MYRSKYLÄ; MARGOLIS, 2014; MIKUCKA; RIZZI, 2019).

No âmbito socioeconômico, destacam-se a maior participação feminina no mercado de trabalho (GUIGINSKI; WAJNMAN, 2019) e a busca crescente das mulheres por um maior nível de escolaridade (ALVES; CAVENAGHI, 2009). Essa última foi proporcionada pela expansão educacional ocorrida no país a partir da década de 1950, ampliando as oportunidades para as mulheres (BELTRÃO; ALVES, 2009; ESTEVE; FLOREZ-PAREDES, 2018). Do ponto de vista da fecundidade, a escolaridade oferece à mulher ferramentas para que ela possa fazer escolhas informadas no que diz respeito, por exemplo, a quando e quantos filhos deseja ter. Ela também aumenta a confiança necessária para que a mulher implemente suas escolhas, mesmo diante de oposições existentes, tanto dentro quanto fora do círculo familiar. Mais 
ainda, uma maior escolaridade pode afetar as aspirações da mulher não somente para si mesma, mas também para a criança (BASU, 2002; FUJIWARA, 2018).

Aliadas a isso, a maior necessidade de autonomia individual, a crescente valorização do trabalho e a ampliação nos níveis de escolaridade e independência econômica feminina, características da segunda transição demográfica (STD), abriram novos caminhos para a realização produtiva da mulher (LESTHAEGHE; 2014). Badinter (1985) enfatiza que as mudanças que ocorreram nas trajetórias disponíveis para as mulheres permitiram que elas questionassem a maternidade e buscassem a plenitude pessoal. Nesse contexto, muitos casais brasileiros contemporâneos se voltaram para a realização de projetos individuais e somente após concretizá-los é que passaram a priorizar projetos conjuntos, como o de ter filhos (BERNARDI et al., 2018). Essa avaliação dos riscos dos eventos produtivos e reprodutivos, como destacado por Giddens (1990), passa a ser utilizada pelas mulheres e pelos casais como uma forma racional de controlar os benefícios e ganhos com as escolhas pessoais que contrastam ideais produtivos e reprodutivos.

A despeito de todas as transformações e novas possibilidades que se descortinaram para as mulheres, a maternidade ainda não pode ser considerada um evento totalmente "fora de moda" para muitas brasileiras. Mesmo após as taxas de fecundidade apresentarem quedas expressivas, atingindo um nível abaixo da reposição em 2004 e chegando a quase 1,8 filho por mulher em 2015 (IBGE, 2017), muitas ainda revelam que gostariam de ter mais filhos do que de fato têm (CARVALHO et al., 2016). Não se pode, no entanto, esperar que a fecundidade no Brasil vá permanecer estável por muito tempo, uma vez que evidências de diferentes estudos têm sugerido um efeito do adiamento do nascimento do primeiro filho (BERQUÓ; GARCIA, 2012; MIRANDA-RIBEIRO et al., 2019) e do aumento da proporção de mulheres sem filho ao final do período reprodutivo ao longo do tempo (LEOCÁDIO, 2018; BERNARDI et al., 2018). Os resultados destes estudos mostram que ainda há muita incerteza sobre a trajetória a ser seguida por essa variável demográfica no país.

Diante do contexto de declínio da fecundidade brasileira em função do efeito tempo (MIRANDA-RIBEIRO et al., 2019) e da influência de choques exógenos - como a reemergência de arboviroses e da crise econômica em curso (MARTELETO et al., 2020) -, é fundamental que se entenda melhor como as brasileiras estão reorganizando seus projetos relativos à maternidade. Ademais, essas mudanças não ocorrem de forma homogenênea nas diferentes regiões do país, o que pode levar a uma complexa gama de projetos reprodutivos.

Estudos que tratam dos desejos relativos à maternidade de forma qualitativa no Brasil apresentam duas principais limitações. Em primeiro lugar, estes trabalhos já mostram certa defasagem temporal, dificultando que se perceba se os projetos relativos à maternidade têm sido atualizados em função das novas dinâmicas (MANSUR, 2003; ROCHA-COUTINHO, 2005; GUEDES, 2008; CARVALHO; VERONA, 2014). Em segundo lugar, os estudos, tanto qualitativos quanto quantitativos, tendem a se concentrar em grandes centros urbanos (ARAÚJO et al., 2018; FUJIWARA, 2018; LEOCÁDIO, 2018), exatamente os locais em que o ritmo de crescimento populacional no Brasil tem diminuido e a fecundidade apresenta 0 
nível mais baixo. Esse último ponto é importante, uma vez que a maior parte da população brasileira vive em municípios de pequeno e médio portes e são nessas localidades que a fecundidade ainda tem potencial para quedas adicionais. Ao se pretender conhecer os desejos e as dificuldades para implementar os projetos relativos à maternidade, são esses os locais que merecem particular atenção.

Por essa razão, o presente estudo analisa as percepções da maternidade para um grupo de mulheres casadas ou em união consensual, sem filhos ou com no máximo um filho, cursando ou já tendo concluído o ensino superior em um município brasileiro de médio porte. ${ }^{1}$ A escolha por esse grupo de mulheres fundamenta-se no fato de que elas são consideradas um grupo de vanguarda nos processos envolvendo a fecundidade (GUEDES, 2008; 2018), especialmente num contexto fortemente privilegiado pela expansão do ensino superior. Além disso, essas mulheres vivem em um município que passou por diferentes crises, incluindo epidemias de arboviroses (GUEDES et al., 2018) e intensos processos migratórios transnacionais (JORGENSEN et al., 2020). Assim, esse trabalho fornece a oportunidade para que se possa entender, em primeira mão, as percepções e os significados atribuídos à maternidade por esse grupo de mulheres que vivem em um contexto marcado por fortes pressões externas, sejam positivas ou negativas.

Para isso, algumas perguntas são exploradas ao longo do estudo: quais são as motivações que essas mulheres apresentam para ter, ou não, filhos? Como a maternidade se conecta aos seus projetos de vida e qual o significado dessa maternidade para as mulheres tanto com filhos como para aquelas que ainda não têm filhos?

Para discutir de maneira mais didática os objetivos propostos, este trabalho está dividido em cinco partes distintas, mas interligadas, sendo a primeira essa introdução, seguida de uma breve revisão de literatura. Posteriormente, além de situar o município que foi foco da investigação, é apresentada a metodologia utilizada no estudo. Analisam-se os resultados obtidos e, por fim, à guisa de conclusão, é feita uma discussão dos resultados à luz da literatura trabalhada.

\section{A maternidade e as transformações sociais: permanências, mudanças e conflitos}

Por muito tempo a maternidade foi vista como o ponto máximo na vida das mulheres, sendo colocada como uma das grandes oportunidades para sua realização pessoal e desempenho do papel que lhes era atribuído como natural. 0 amor materno era considerado algo inato, inquestionável e que gerava um desejo por filhos. Os estudos de Badinter (1985), Laney et al. (2015), Trindade et al. (2016), Azevedo (2017) e também de Visintin e Aiello-Vaisberg (2017) enfatizam questões relacionadas ao mito estabelecido em torno do desejo das mulheres de se tornarem mães. As expectativas sociais reforçaram, durante muito tempo, o papel materno da mulher como uma condição central para sua identidade

\footnotetext{
${ }^{1}$ De acordo com o Instituto Brasileiro de Geografia e Estatística (IBGE), um município de médio porte é aquele que possui entre 100 mil e 500 mil habitantes.
} 
feminina (ROCHA-COUTINHO, 2005; ODENWELLER; RITTENOUR, 2017; MACHADO et al. 2019) e criaram um ambiente social em que questionar o papel da mulher enquanto mãe ainda constitui desafio (TRINDADE et al., 2016; VISINTIN; AIELLO-VAISBERG, 2017). Os ideais de amor romântico, encarados como um compromisso ativo e radical com o machismo da sociedade moderna, tiveram um papel central em reforçar a figura do lar como o lócus natural da realização feminina (GIDDENS, 1993). Esperavam-se das mulheres atributos como passividade, afabilidade, dedicação e abnegação. Não raro, identificava-se feminilidade com maternidade (BADINTER, 1985; GUIMARÃES, 2010; MACHADO et al., 2019).

Mudanças em diferentes esferas, no entanto, impulsionaram nas mulheres outros desejos para além da maternidade. Os debates sociológicos e demográficos clássicos acerca das razões para se ter filhos desejados lançam mão de explicações econômicas, como a vantagem financeira de ter crianças para ajudar no trabalho doméstico e no cuidado futuro na velhice (WILLS, 1982; CALDWELL, 2005), explicações psicológicas e emocionais, como a do altruísmo e da antecipação das recompensas afetivas (BARRO; BECKER, 1989; BECKER, 1992; BLACKBURN; CIPRIANI, 2005), e explicações culturais, como o status da criança em cada sociedade e o capital social que dela advém (MORGAN; KING, 2001). As diferentes motivações, que não são necessariamente as mesmas a cada nova ordem de nascimento, têm sido então utilizadas para explicar mudanças tanto no tamanho ideal de família quanto nas decisões para ter um filho adicional.

Atualmente, para países com fecundidade abaixo do nível de reposição, o arcabouço da segunda transição demográfica (STD) pontua que as decisões relacionadas ao número de filhos estão sob a influência de novos valores e necessidades da sociedade, como o aumento da autonomia individual, o reconhecimento e a tolerância e o surgimento do pós-materialismo (LESTHAEGHE; VAN DE KAA, 1986; VAN DE KAA, 1987; LESTHAEGHE; SURKYN, 1988). Mikucka e Rizzi (2019) e Myrskylä e Margolis (2014) sugerem que a satisfação das mulheres pode advir de trajetórias individuais que não colocam o projeto reprodutivo como central. Adserà (2015) reforça esse argumento ao associar a secularização à adoção de padrões de comportamento próximos dos descritos pela STD, apontando para o papel do aumento da autonomia feminina e da diminuição das crenças religiosas mais tradicionais sobre a alteração no desejo por filhos.

A organização do curso de vida também se tornou menos padronizada, assim como se tornaram mais aceitos os múltiplos estilos de vida (LESTHAEGHE, 2014), entre eles os que não contemplam a maternidade, como entre os casais de dupla renda e sem filhos (ALVES et al., 2010). Bernardi et al. (2018) enfatizam que, ao longo do tempo, houve mudanças no projeto parental dos casais, os quais passaram a priorizar projetos individuais, embora o desejo pela parentalidade não tenha desaparecido. Essa permanência do desejo, associada a uma mudança no número de filhos em função da dificuldade de conciliação dos projetos individuais e conjugais, é vista como fonte de conflito, particularmente para as mulheres. 0 conflito em si reflete uma complexa dinâmica entre trajetórias individuais 
e coletivas, sugerindo que escolhas aparentemente individuais são em parte reflexo do contexto coletivo e das interações interpessoais em que as mulheres se inserem (GIDDENS, 1990; VELHO, 2003).

Laney et al. (2015) salientam que ter um filho significa o estabelecimento de uma relação intensa e de longa duração para a mulher e faz com que ela precise não somente reavaliar dimensões de sua vida, como autonomia e ocupação, mas também repensar quem ela é em relação ao outro. As expectativas sociais reforçaram, durante muito tempo, o papel materno da mulher como uma condição central para sua identidade feminina (ROCHA-COUTINHO, 2005) e criaram um ambiente social em que questionar o papel da mulher enquanto mãe ainda constitui um desafio (TRINDADE et al., 2016). Por essa razão, a maternidade demanda um esforço no sentido de integrar noções internalizadas sobre a mãe ideal e a mãe real para evitar que a distância entre esses pontos gere sentimentos de ansiedade, culpa e dúvidas.

Apesar disso, o desejo por mais liberdade, lazer e bens de consumo, a isenção de responsabilidade de cuidar de uma criança, a oportunidade para autorrealização e livre mobilidade são motivos citados para não ter filhos, o que também proporciona à mulher maior liberdade para participar do mercado de trabalho e, ao homem, a independência do cuidado com os filhos (AGRILLO; NELINI, 2008).

Pesquisas com representatividade nacional, realizadas em 2003 e 2016-2017, mostram que, embora tenham ocorrido mudanças na divisão do trabalho doméstico nos últimos anos, essas foram pouco expressivas, pois ainda cabe à mulher a responsabilidade pela maior parte dos trabalhos no âmbito domiciliar, principalmente no que se refere ao cuidado dos filhos (ARAUJO et al., 2018). Gama et al. (2018) destacam o aumento das preferências por igualdade entre as mulheres mais escolarizadas e que se inserem em melhores posições no mercado de trabalho, exigindo que esses ideais de igualdade de gênero sejam replicados na esfera privada. As permanências da desigualdade de gênero na divisão do trabalho doméstico resultam, portanto, em um desincentivo ao projeto reprodutivo, favorecendo tanto o adiamento quanto a decisão por não ter filhos (GUIGINSKI; WAJNMAN, 2019).

A despeito da expansão educacional vivenciada pelo Brasil nas últimas décadas, com ganhos mais expressivos para a população feminina, Araújo et al. (2018) verificaram que indivíduos que trabalham mais de $\mathbf{4 0}$ horas semanais e jovens mais escolarizados são os que revelam comportamentos mais conservadores nessa esfera. Tal resultado instiga reflexões acerca das motivações para esse aparente contrasenso. Fatores como efeitos de composição relacionados à mudança no perfil religioso - com especial crescimento do grupo de evangélicos entre os mais escolarizados (BORGES, 2018) - e a qualidade da educação experimentada nos últimos anos são possíveis caminhos para se entender melhor as mudanças e as permanências relativas ao desejo pela maternidade.

As novas possibilidades geradas pela conquista de níveis mais elevados de escolaridade pelas mulheres, o desejo de construir uma carreira profissional mais sólida e de maior prestígio, além das rotinas de trabalho, se tornam aspectos concorrentes com a 
maternidade (GUEDES, 2008). Embora esse aumento no nível da escolaridade tenha tido um impacto negativo sobre a intenção reprodutiva e o timing da fecundidade (FUJIWARA, 2018; BERQUÓ; CAVENAGHI, 2006, 2014; RIOS-NETO; GUIMARÃES, 2014; COUTINHO, 2016), Esteve e Florez-Paredes (2018) chamam a atenção para um paradoxo da estabilidade experimentado por vários países latino-americanos, incluindo o Brasil.

Os autores observaram que a expansão dos níveis educacionais entre as novas coortes tiveram papel limitado em reduzir a fecundidade de forma tão rápida quanto seria esperada. As mulheres continuam casando cedo e tendo o primeiro filho em idades bastante jovens. A reduzida qualidade da educação e a dificuldade desta em se transformar em oportunidades reais no mercado de trabalho são as principais razões apontadas por Esteve e Florez-Paredes (2018) para a existência desse paradoxo, podendo impactar na elaboração dos projetos de vida dos indivíduos (VELHO, 2003).

Diante do claro espraiamento das universidades, da possível disseminação do comportamento de baixa fecundidade e das lacunas que ainda se mantêm no conhecimento sobre as razões e motivações para ter ou não filhos, este artigo busca contribuir para a ampliação do entendimento de questões relacionadas às intenções reprodutivas entre mulheres de alta escolaridade em municípios de porte médio. Pouco se conhece sobre o comportamento deste grupo de mulheres vivendo nos locais que lideram o potencial de crescimento populacional no Brasil.

A análise é feita a partir de discursos relativos às motivações, incertezas e expectativas quanto à maternidade, bem como acerca dos significados da maternidade no contexto dos projetos de vida das mulheres entrevistadas. Os estudos brasileiros que tratam de questões relacionadas tanto a projetos de vida quanto a decisões relativas a ter ou não filhos se concentram, majoritariamente, nos grandes centros urbanos do país, deixando um hiato sobre a realidade que caracteriza municípios de médio porte, como é o caso de Governador Valadares (MG), escolhido para o estudo.

\section{Metodologia}

Os resultados apresentados neste estudo são provenientes de uma investigação realizada em Governador Valadares, município mineiro localizado a 320 km de Belo Horizonte, capital do estado. De acordo com informações do Atlas do Desenvolvimento Humano 2013, elaborado pela Fundação João Pinheiro, a população do município era de 263.689 habitantes em 2010, sendo 125.237 (47,5\%) homens e 138.452 (52,5\%) mulheres.

Ao mesmo tempo que o município experimentou um aumento na proporção de mulheres com ensino superior, a taxa de fecundidade total (TFT) permaneceu inalterada (2,1 filhos por mulher) entre 2000 e 2010 (FJP, 2013). Esse cenário de permanência da TFT é curioso, pois a expectativa é de que grupos de vanguarda, tal como o de mulheres de alta escolaridade, revelassem comportamentos diferenciados em relação ao projeto reprodutivo. Isso torna Governador Valadares um caso interessante para o estudo dos projetos relativos à 
maternidade. A inexistência de dados quantitativos que abordem experiências, expectativas e desejos exige a coleta de dados qualitativos relacionados aos projetos reprodutivos.

As informações utilizadas neste estudo foram coletadas por meio de entrevistas semiestruturadas, realizadas em junho de 2018 com 16 mulheres residentes na área urbana do município. A entrevista semiestruturada é uma técnica que possibilita uma interação ativa entre indivíduos, permitindo que compreensões subjetivas, experiências e percepções de interesse do pesquisador sejam exploradas. Por não impor uma categorização a priori das respostas, ela permite um entendimento mais detalhado do conhecimento, das memórias e das percepções dos entrevistados (HAMMET et al., 2015).

Para a realização das entrevistas, foi elaborado um roteiro contendo 37 perguntas distribuídas em cinco blocos, que contemplavam os seguintes aspectos: casamento, filhos, contracepção, despesas domésticas, divisão de tarefas, saúde, religião e vida em Governador Valadares antes e depois da tragédia da Samarco. As entrevistas foram realizadas com mulheres que tinham, na época da pesquisa, entre 22 e 33 anos, eram casadas ou unidas, ${ }^{2}$ sem filhos ou com, no máximo, um filho nascido vivo e que foram as primeiras de suas famílias de origem a conquistarem o ensino superior. A escolha por esse grupo fundamenta-se no fato de que o aumento na escolaridade tem ampliado o leque de possibilidades para as mulheres em diferentes esferas e feito com que muitas questionem o desejo pela maternidade. Ademais, a escolha pelas mulheres casadas ou unidas há, no máximo, seis anos deu-se para que se pudesse captar o momento em que as decisões reprodutivas são de fato feitas. Assim, das entrevistadas, 13 possuíam ensino superior completo e três estavam cursando esse nível de ensino pela primeira vez. A seleção das participantes aconteceu por meio de estratégias de conveniência. Foram utilizadas redes de contatos e de conhecimentos para que a mulher fosse convidada a participar do estudo. 0 Quadro 1 apresenta a descrição sociodemográfica das participantes do estudo. Os nomes atribuídos às entrevistadas são fictícios.

As entrevistas foram gravadas e, posteriormente, transcritas para análise. Todas as entrevistadas assinaram um Termo de Consentimento Livre e Esclarecido (TCLE), declarando ter recebido informações sobre os objetivos e procedimentos da pesquisa, inclusive sobre a gravação e o sigilo da identidade e das informações fornecidas. A análise do material foi desenvolvida a partir da proposta de Attride-Stirling (2001) denominada análise de redes temáticas e incluiu seis passos: codificação do material; identificação dos temas; construção das redes temáticas; descrição e exploração das redes temáticas; sumarização das redes temáticas; e interpretação. A partir da codificação do material, foram estabelecidas e analisadas as categorias analíticas aqui apresentadas, as quais permitiram conhecer mais profundamente fatores que interferem no desejo de ter ou não filhos e nas percepções acerca da maternidade. Importante esclarecer que, considerando os preceitos éticos que

\footnotetext{
${ }^{2}$ A opção por incluir tanto mulheres casadas quanto em união deve-se ao fato de o reconhecimento jurídico da união consensual, como aponta Vieira (2016), ter sido acompanhado por um processo de desestigmatização social.
} 
guiam as investigações que envolvem seres humanos, o estudo foi submetido e aprovado pelo Comitê de Ética em Pesquisa (CAAE 55007116.7.1001.5149).

QUADRO 1

Caracterísitcas sociodemográficas das mulheres entrevistadas

\begin{tabular}{|cccccc|}
\hline Entrevistadas & Idade & Situação & Tempo casada/unida & Filhos & Escolaridade \\
\hline Ana & 22 & Casada & 3 anos & 0 & Superior incompleto \\
Anita & 30 & Casada & 5 anos & 0 & Pós-graduação \\
Bela & 31 & Casada & 3 anos e 2 meses & 0 & Pós-graduação \\
Cissa & 29 & Unida & 2 anos e meio & 0 & Superior completo \\
Clara & 33 & Casada & 5 anos & 0 & Pós-graduação \\
Cleo & 26 & Casada & 6 anos & 0 & Superior completo \\
Diná & 22 & Casada & 1 ano & 0 & Superior completo \\
Duda & 25 & Casada & 3 anos & 0 & Superior incompleto \\
Flora & 32 & Casada & 10 meses & 0 & Pós-graduação \\
Iris & 25 & Casada & 3 anos & 0 & Superior completo \\
Jade & 24 & Casada & 3 anos & 0 & Superior incompleto \\
Lais & 33 & Casada & 2 anos & 0 & Superior completo \\
Lara & 32 & Casada & 2 anos & 1 & Pós-graduação \\
Lola & 33 & Casada & 1 ano e 9 meses & 0 & Pós-graduação \\
Luna & 28 & Casada & 4 anos & 0 & Superior completo \\
Nina & 32 & Casada & 2 anos & 1 & Pós-graduação \\
\hline
\end{tabular}

Fonte: Elaboração dos autores.

Os dados coletados para este estudo fazem parte de um projeto mais amplo, denominado Demografia da Exceção: Intenções Reprodutivas e Migração em um Contexto de Zika Vírus e Desastres Socioambientais. 0 referido projeto conta com financiamento do CNPq (processos 431871/2016-3 e 314392/2018-1), da Fapemig (APQ 01553-16) e da Rede Clima/Finep (01.13.0353-00).

\section{Resultados}

As percepções apresentadas pelas entrevistadas são analisadas a seguir e revelam, em diversos extratos de falas, mudanças, permanências e conflitos em relação às motivações para a maternidade e aos significados a ela atribuídos pelo grupo de mulheres analisado. Seus pontos de vista acerca de desejos, incertezas, temores e outros sentimentos que afloram quando se fala sobre maternidade estão dispostos a seguir.

"Poder ser mãe... acho que a maioria carrega esse desejo"

A maternidade ainda é um aspecto central nas sociedades atuais. A expectativa de que um casal tenha filhos parece ser a norma, enquanto o desejo de não ter filhos é, usualmente, percebido como algo pouco aceitável, que foge aos padrões de comportamento desejado para mulheres (McQUILLAN et al., 2008). Badinter (1985) chama a atenção para o fato de que a maternidade ainda é considerada um padrão natural e 
intrínseco da mulher, embora ela deva ser reconhecida como uma construção histórica e social. Para muitas entrevistadas neste trabalho, a maternidade ainda é apontada como um evento esperado na vida das mulheres, particularmente das casadas. A justificativa para a maternidade aparece normalmente ancorada em quatro pontos: a realização como mulher e a sua inclinação natural para ser mãe; a pressão familiar; a religiosidade; e o desenvolvimento enquanto ser humano.

Alguns extratos de falas apontam que o desejo pela maternidade é tido como algo que aflora naturalmente, com o passar do tempo e da idade e, especialmente, após uma união. Realizar-se enquanto mulher é considerada uma das vantagens da maternidade e o filho é visto como alguém que chega para trazer alegrias e "somar” à relação. Além disso, a despeito da contestação feita por Badinter (1985), de que o instinto materno é um mito, ele aparece como uma das justificativas para que uma mulher, mesmo acreditando que não tenha afinidade com crianças e se sinta receosa em relação às mudanças trazidas pela maternidade, possa querer se tornar mãe em algum momento de sua vida.

Eu não tenho muita afinidade com bebê, mas eu sei que eu vou ter porque a gente aprende naturalmente. A gente já tem o instinto. (Anita, 30 anos, casada há 5 anos, sem filhos)

Primeiramente, eu acho que o sonho de toda mulher é ser mãe. E mais pela minha profissão, eu sou professora eu lido com criança o tempo todo. Então eu cuido dos filhos dos outros e não vejo a hora de cuidar dos meus. Eu libero toda a tensão do mundo com os filhos dos outros, eu quero ter essa experiência de, ao invés de cuidar dos filhos de outras mães, cuidar dos meus filhos. (Diná, 22 anos, casada há 1 ano, sem filhos)

Eu tenho 33 anos, vou fazer 34, e aí começo eu mesma me cobrar, fora a minha mãe que me cobra todos os dias porque o sonho dela é ser avó. Aí a gente sempre falou, como uma coisa futura, mas não como presente. Aí, antes do casamento nunca pensou em ter filhos, mas depois que casou, eu falo mais, mas agora ele também tem demonstrado o desejo... Eu acho que as vantagens são a realização enquanto mulher. Poder ser mãe, acho que a grande maioria carrega esse desejo. Hoje está mudando um pouco. Tenho várias [amigas] que não pensam. Mas também têm várias que não pensavam antes e agora já pensam. Eu amo meu marido, a gente está junto desde 2011. Acho tudo ótimo, e acho que filho só vem pra trazer alegria, pra somar. Não que esteja faltando alguma coisa no casamento, mas ele vem para agregar. (Lola, 33 anos, casada há 1 ano e 9 meses, sem filhos)

0 importante papel que a maternidade ainda parece ter na vida das mulheres emerge nos argumentos das entrevistadas, as quais a colocam como um sonho, senão de todas as mulheres, pelo menos da maioria. Além disso, as falas sugerem que a maternidade entra mais claramente em pauta quando a idade começa a se apresentar como um fator condicionante de fertilidade feminina, como observado por Bernardi et al. (2018).

Aliada aos aspectos mencionados, a pressão familiar aparece fortemente atrelada ao projeto da maternidade, especialmente depois de transcorrido algum tempo do relacionamento, indicando, como afirma Badinter (1985), que a maternidade constitui um dos mitos da nossa cultura, exercendo papel expressivo sobre a vida das mulheres, que são educadas e cobradas desde muito cedo em relação à inclusão da maternidade em suas 
vidas. A cobrança social, mesmo que silenciosa em alguns casos, faz-se presente na vida das mulheres que "ousam" trilhar uma trajetória diferente da esperada, como observou Mansur (2003). Os relatos de Bia e Bela ilustram esses aspectos.

Tem muita cobrança também. Dos pais, dos sogros, das amigas, dos irmãos. Minha irmã aqui tá grávida e meu irmão teve um neném. E eu fui a que casei primeiro. Sou a mais nova e a que casou primeiro. A cobrança vem aí, desse tempo de casada. Mas nada que influencia minha decisão. Quando a gente entendeu que tava na hora a gente começou a tentar. (Bia, 28 anos, casada há 8 anos, sem filhos)

Aí, a gente conversando [a entrevistada com amigas], elas ficam me cobrando. Porque existe isso. A sociedade cobra, as amigas cobram. Aí eu falo com elas que elas estão dentro da piscina fria gritando: pula, a água tá quentinha. É desse jeito. Estão todas de olheira, cansadas, estressadas, brigando com o marido, “mas vem que tá bom!” (Bela, 31 anos, casada há 3 anos e 2 meses, sem filhos)

Assim como as pressões vindas da família e de amigos, a religião também surge como um aspecto que interfere na decisão de ter ou não filhos. Religiões que apresentam uma postura pró-natalista parecem ter um efeito na maneira como entrevistadas mais religiosas se posicionam não somente quanto à maternidade e à possibilidade de não terem filhos, mas também sobre o aborto e a relação entre casamento e filhos. Ao discutirem sobre a questão, Carvalho e Verona (2014) lembram que estudos realizados em diversos países europeus e nos Estados Unidos mostram que as instituições religiosas e a identidade religiosa dos indivíduos podem influenciar a fecundidade e as preferências reprodutivas. Em seus resultados, as autoras observam que as mulheres evangélicas e também aquelas que se declaravam como sem religião tinham maiores chances de terem mais filhos nascidos vivos, quando comparadas a mulheres de outras religiões. Neste estudo, as entrevistadas que apresentam um discurso religioso revelam não somente uma valorização do modelo de família tradicional ou nuclear, como também uma ênfase no casamento religioso, definido como "instituído por Deus". Trindade et al. (2016) lembram que ainda hoje, em diversos contextos, a definição de feminino remete à gravidez e muitas religiões cristãs exaltam 0 papel da maternidade.

Eu não falo a religião, mas os mandamentos de Deus, as promessas de Deus mesmo. $\mathrm{Na}$ verdade, eu entrei pra igreja tem pouco tempo, mas eu sempre busquei a luz e Deus fala muito sobre filhos. Filhos são heranças do senhor. E o casamento é instituído por Deus. Se eu quis casar e constituir uma família, é natural que eu venha ter filhos. Família de dois não é família. Eu quero uma família completinha. Eu vim de uma que não fui criada com pais. Antes de casar eu não pensei, mas depois, eu pensei o quanto era importante ter uma família estruturada, com pai, mãe, irmãos. (Duda, 25 anos, casada há 3 anos, sem filhos)

A gente que é religiosa, a gente é a favor da vida. Igual, eu sou católica. Eu não sou a favor do aborto. Deus deu a vida não pra tirar. E como eu cresci na igreja e gosto de criança. (Ana, 22 anos, casada há 3 anos, sem filhos) 
Entre as maiores justificativas para se tornarem mães, estão aquelas ligadas às oportunidades para se desenvolverem enquanto pessoa. Tanto as entrevistadas que já são mães quanto aquelas que não o são atribuem um significado especial para a maternidade. Como enfatiza Badinter (1985, p. 9), apesar das inúmeras mudanças ocorridas na sociedade, “a maternidade é, ainda hoje, um tema sagrado". Não ser mãe implica a não realização de um potencial e o desvio de uma norma secular (MANSUR, 2003) e, como sugerem Esteve e Flores-Parede (2018), nem sempre a maior escolaridade - que cria novas possibilidades de projetos de vida - impulsiona o desejo por adiamento à maternidade, fato que pode ser considerado um paradoxo.

De maneira geral, tornar-se mãe é algo valorizado pelas mulheres, particularmente por aquelas que já o são. Ter um filho significa ser "abençoada” e implica mudar a maneira de ver as outras pessoas e o mundo. Valorizar mais a vida, ter mais respeito pelas pessoas, perceber os problemas de maneira diferente, sentir-se mais completa enquanto indivíduo e adotar um modo de vida mais saudável são pontos citados como alguns resultados positivos advindos da maternidade em si ou da expectativa de se tornar mãe. Para Laney et al. (2015), uma das mudanças mais expressivas que acontece na vida de uma mulher quando ela se torna mãe é o fato de que a maternidade parece intensificar suas experiências pessoais e emocionais. As falas de Lara e de Nina ilustram esses pontos.

Pra mim é uma benção porque eu era uma pessoa feliz. Mas só que é diferente. É uma pessoa que tem seus traços. Muda sua vida. Muda a sua casa, sua maneira de ver as outras pessoas. Eu estou uma pessoa mais sensível com relação às outras pessoas. Eu vim de uma família católica praticante e meus pais sempre fizeram caridade. E você vai caminhando e tal. Mas depois que você tem filho, você se compadece mais das pessoas. Eu me vejo assim [...] o que acontece com os filhos dos outros mexe com você. Eu penso, poderia ser com ela. (Lara, 32 anos, casada há 2 anos, 1 filho)

Ser mãe ajuda a gente a ter uma outra visão de mundo. Da questão de valorização da vida, do respeito às pessoas, e do que é maior. Porque é um amor totalmente diferente. É um amor diferente do de marido. Torna alguns problemas que eu tinha daí pra trás, zero. Aquilo ali nunca foi problema, isso aqui pode se tornar um problema. Um filho gripado pra uma mãe é o fim do mundo. Isso antes pra mim... Aí você passa a dar importância pras coisas que são maiores, relativos a sentimento, convivência, muito mais do que antes. (Nina, 32 anos, casada há 2 anos, 1 filho).

A percepção das entrevistadas remete às considerações feitas por Kohler (2016) de que ter filhos é motivo de satisfação e alegrias. 0 desejo por ter filhos e pela experiência da parentalidade, no entanto, é marcado por sentimentos de incerteza acerca do que está por vir com a chegada de um filho. Giddens (1993) ressalta que, à medida que as famílias se tornaram menores, o controle das mulheres sobre a criação dos filhos aumentou e a afeição maternal passou a ser colocada no centro da família, criando uma pressão ainda maior sobre o papel das mulheres no sucesso e estabilidade do núcleo familiar. Os relatos apresentados na próxima seção ilustram esse argumento. 


\section{"Daqui um tempo vamos ver como as coisas vão ficar"}

Apesar de o desejo pela maternidade ser visto como natural por algumas mulheres e especialmente reforçado pelas famílias de origem, pelos grupos de amigos e por preceitos religiosos, os relatos de grande parte das entrevistadas deixam evidente que o desejo de se tornar mãe, principalmente relacionado ao timing, pode se modificar durante a trajetória de vida da mulher. Como apontam McQuillan et al. (2008), transformações em circunstâncias de vida, tais como a entrada ou saída de uma união estável, o início ou finalização de um projeto educacional e a possibilidade de ter uma carreira, podem levar as mulheres a repensarem seus planos familiares.

Embora muitas entrevistadas reconheçam que possuem liberdade de escolha em relação aos acontecimentos familiares e profissionais, elas também têm ciência de que a tríade casamento, ascensão profissional e filhos requer uma organização. É nesse momento que a possibilidade de cursar o ensino superior e usufruir dos novos padrões de vida que isso pode oferecer, como viajar e "aproveitar a vida a dois", transforma completamente a experiência da mulher com a maternidade e pode influenciar o adiamento da fecundidade.

Eu vejo assim: eu tenho uma liberdade pra sair... Ah, mas não é só isso. Isso é muito pequeno. Mas eu vejo assim uma liberdade de escolher... Eu não sei te explicar, é uma coisa difícil. Mas assim, eu tenho a liberdade de escolher não ter filhos, a opção de poder fazer outras coisas, me dedicar a outras coisas. Me dedicar a outras coisas e não me dedicar à maternidade, de poder escolher isso. (Cissa, 29 anos, unida há 2 anos e meio, sem filhos)

Quando a gente casou, a gente não queria ter filhos imediatamente, né?! A gente queria, primeiro, curtir um pouco, viajar, essas coisas. A gente gosta muito de viajar... (Luna, 28 anos, casada há 4 anos, sem filhos).

Ter um filho sem a devida organização implica abrir mão de coisas consideradas importantes e assumir custos expressivos, já que a maternidade pode se configurar como um evento que compete com outros também desejados. De acordo com Fujiwara (2018), estudar e avançar na carreira, assim como aproveitar outras coisas da vida antes da maternidade, são os principais motivos para que uma grande parcela das mulheres brasileiras queira adiar a maternidade ou permanecer sem filhos. Carvalho et al. (2016) também observam que conquistas educacionais influenciam fortemente o número de filhos que as mulheres decidem ter. De acordo com as autoras, mulheres mais escolarizadas, especialmente aquelas com 12 anos ou mais de estudo, têm um número menor de filhos do que gostariam de ter. Os relatos apresentados a seguir ilustram esta questão.

No início a gente pensou em esperar um ano, dois anos, pra dar um tempinho e aproveitar, mas com o tempo vieram outras prioridades, como uma conta ou um sonho que se quer realizar. E surgiu a oportunidade de fazer o curso de pedagogia e fiquei muito empolgada. Aí ele falou: se você quiser fazer o curso, você tem todo o meu apoio, mas vai ter que esperar um pouquinho pra maternidade. Eu aceitei, mas fiquei pensando. Quando 
começou o curso eu vi que tem a família, tem o trabalho, e não ia dar muito certo uma gestação naquele momento e esperamos até agora, que eu vou concluir. Formo agora, essa semana e agora vamos planejar o que a gente deixou pra trás, que é o filho. (Cleo, 26 anos, casada há 6 anos, sem filhos)

Hoje, eu acho que a minha agenda [de trabalho] é mais flexível por isso. Eu posso mudar da manhã para tarde, da tarde para a noite, que está tudo bem. Tendo um filho, eu acho que isso não tem condição de acontecer. As dificuldades eu acho que são tantas... Isso, de manter uma rotina. Uma pessoa que viveu tanto tempo sozinha, tanto tempo só ela e o marido e ter que se adaptar a essa nova pessoa, esse novo ser na vida, então deve ser muito complicado. (Flora, 32 anos, casada há 10 meses, sem filhos)

Outro fator considerado importante no desejo por filhos diz respeito à estabilidade financeira. Várias mulheres que participaram do estudo pertencem a famílias de baixo poder aquisitivo e, por essa razão, consideram essencial ter uma casa e condições econômicas estáveis para arcar com os custos de uma criança. Bernardi et al. (2018) enfatizam que a conquista da estabilidade financeira exige constante investimento em capacitação pessoal, levando muitos casais a repensarem o projeto da maternidade. Ter um filho requer um afastamento de atividades consideradas relevantes, como estudo e trabalho, especialmente por parte das mulheres.

Minha família é grande. Somos doze irmãos. Tivemos uma vida financeira muito difícil e eu queria sair dessa vida. (Lais, 33 anos, casada há 2 anos, sem filhos)

Mas a questão financeira pesa muito. Eu penso assim: hoje eu me viro com ele. A gente paga todas as contas e eu não devo a ninguém, mas pra ter uma terceira pessoa, que vai precisar de muito cuidado e atenção... como é que eu vou fazer? Então a gente pensa assim: é uma questão racional. Se para dois tá difícil, como é que eu vou colocar mais um? (Clara, 33 anos, casada há 5 anos, sem filhos)

A organização do mercado de trabalho e a divisão das tarefas no âmbito doméstico são aspectos que não facilitam a tomada de decisão das mulheres quanto à maternidade (GAMA et al., 2018). Apesar das mudanças nos comportamentos e papéis de gênero nos relacionamentos atuais, os ajustes exigidos das mulheres ainda são consideráveis. Muitos casamentos ainda são baseados na divisão sexual convencional entre a esposa doméstica e o provedor masculino, o que dificulta a eliminação dos diferenciais de gênero no uso do tempo e do conflito produção/reprodução no âmbito feminino (GIDDENS, 1990). Além disso, as inseguranças sobre a capacidade para assumir todas as responsabilidades que o nascimento e a criação de um filho impõem ao casal, mas particularmente à mulher que se torna mãe, também emergem nos discursos. Isso não impede que o desejo de ser mãe continue a existir, mas os projetos de vida que refletem sua reprodução material assumem um lugar preponderante, gerando um adiamento da intenção reprodutiva. É nesse espaço que diferentes desejos podem ser motivos de conflitos e dúvidas. 


\section{"Eu tenho medo da responsabilidade..."}

Embora a maternidade ainda faça parte dos sonhos e projetos de vida de muitas entrevistadas, para algumas ela não é encarada como um acontecimento obrigatório e que resulta em felicidade e realização. Mulheres sem filhos podem encontrar caminhos alternativos ao da maternidade para alcançar a tão esperada realização pessoal (MYRSKYLÄ; MARGOLIS, 2014; MIKUCKA; RIZZI, 2019). Sentimentos de bem-estar e felicidade podem estar vinculados à possibilidade de estudos e ascensão profissional, tal como constatado em diferentes trabalhos (AGRILLO; NELINI, 2008; McQUILLAN et al., 2008) e nas falas a seguir.

Ter filhos e fazer faculdade é difícil demais! Ou eu teria filhos ou eu sairia da faculdade! Não tem como encaixar um filho nessa situação! (Jade, 24 anos, casada há 3 anos, sem filhos)

Então, assim, queremos ter, mas até hoje a gente não teve porque eu estou me formando. Quando eu me casei estava no quinto período da faculdade, hoje eu já estou no décimo... Então, agora assim que eu formar eu pretendo fazer uma pós, um mestrado, quem sabe?! (Íris, 25 anos, casada há 3 anos)

No meu caso, eu tenho dificuldades. Não que eu não queira ter filhos, mas por causa da responsabilidade...é que aí entra aquela coisa de ser para sempre, da dependência do outro.......] Eu tenho algumas amigas que não tiveram. Algumas mais velhas. Parte não teve porque não teve oportunidade, mas que são louca para ter e sentem falta disso. Parte não. Essa parte tem projeto de vida, e elas estão super felizes. Trabalho, estudo, concurso, viagem. Então tem muito disso. (Bela, 31 anos, casada há 3 anos e 2 meses, sem filhos)

Adicionalmente, o conflito entre a existência de um instinto materno e as dificuldades impostas pela rotina diária de cuidados com o bebê torna as mulheres mais cautelosas em relação à decisão sobre ter ou não filhos. Algumas falas sugerem que os cuidados com a criança são intensivos em termos tanto de gastos quanto de tempo e ainda permanecem como uma responsabilidade da mãe. Scavone (2001) salienta que a maternidade ainda é um dilema para as mulheres que querem ampliar o capital humano por meio dos estudos e seguir uma carreira profissional. Isso ocorre porque ainda são elas as que assumem a maior parte das responsabilidades de cuidados com a criança. Diferentemente do que ocorre em países desenvolvidos, a equidade na responsabilidade parental ainda não se consolidou no Brasil.

Para além do dilema entre investimento em capital humano e maternidade, Laney et al. (2015) argumentam que a relação entre mãe e filho é longa e intensa e há uma expectativa social formada de que as mulheres devam sempre ter sentimentos positivos sobre isso. Na verdade, a maternidade requer que a mulher reavalie e reorganize várias áreas de sua vida e, muitas vezes, sua confiança fica abalada em função dos ideais de maternidades difundidos culturalmente.

E pra tudo na vida eu penso se eu vou ter condição de dar conta do negativo. Se eu vou ter estrutura para dar conta [...] Eu tenho medo da responsabilidade. Do ser para sempre. Da dependência que o outro tem. Por mais que os filhos cresçam, eu não sei até que fase, mas você tem sempre que cuidar do outro. Tudo que acontece é sua responsabilidade. (Bela, 31 anos, casada há 3 anos e 2 meses, sem filhos) 
Filho... me pergunto muito se eu daria conta. Por que eu acho que é muita responsabilidade você ter um filho, você criar filho. Eu penso na rotina, nos mínimos detalhes ali, sabe? E eu sou meio desesperada assim, meio apavorada. Aí eu fico pensando: vou sufocar o meu filho de tanto cuidado, entendeu? (Clara, 33 anos, casada há 5 anos, sem filhos)

A preocupação em relação aos padrões de ética e moral que se apresentam nas sociedades atuais e seus reflexos no futuro também aparece como motivo para evitar a maternidade. Para algumas mulheres, a decisão de ter filhos vai além do medo das mudanças na rotina cotidiana, sendo também influenciada por como percebem questões sociais que permeiam a realidade brasileira, como a crise econômica e política. Segurança e saúde, desigualdade nas relações de gênero e estruturas educacional e de mercado desfavoráveis às mulheres são fatores que fazem com que elas reflitam sobre o desejo de se tornarem mães. A fala de Jade, uma das entrevistadas, é um exemplo que expressa esse tipo de percepção.

Eu acho que os padrões de moral e ética da sociedade me preocupam muito. Porque essa sociedade que gente vive hoje, a gente já vê tanta mazela, tanta coisa ruim. Penso, o que será dos meus filhos quando eles chegaram na minha idade? (Jade, 24 anos, casada há 3 anos, sem filhos)

Scavone (2001) lembra que, mesmo com maior acesso à educação formal e à formação profissional e ocupando cada vez mais os espaços públicos, as mulheres não experimentaram um relaxamento expressivo concomitante na responsabilidade de criação dos filhos. Isso fez com que se tornassem mais reflexivas acerca do significado e impacto da maternidade sobre suas vidas. Não é por acaso que evidências internacionais apontam que a felicidade das mulheres não depende exclusivamente do projeto que inclua a escolha por filhos, ou, até mesmo, pela união (GUIGINSKI; WAJNMAN, 2019; MA; PIAO, 2020). 0 mundo vem passando por muitas transformações, e as mulheres já não aceitam passivamente os papéis tradicionais a elas atribuídos. Em um mundo onde se deseja maior igualdade, homens e mulheres são levados a realizarem mudanças não somente em seus pontos de vista, mas também em seus comportamentos em relação um ao outro, trazendo novas experiências sociais ao cotidiano (GIDDENS, 1993).

\section{Considerações finais}

O presente trabalho teve como objetivo analisar as percepções e os significados atribuídos à maternidade entre um grupo de mulheres de alta escolaridade, casadas ou unidas, sem filhos ou com apenas um filho, residentes em Governador Valadares, um município mineiro de porte médio. Tem-se clareza de que os resultados aqui apresentados não são passiveis de generalização e expressam apenas reflexões feitas por um grupo específico de mulheres. Apesar disso, acredita-se que eles abrem espaço para a construção de novas hipóteses que guiem estudos acerca de limites e possibilidades gerados pela escolarização nos diferentes projetos de vida de mulheres escolarizadas no mundo moderno, incluindo o da maternidade. 
As análises dos relatos das participantes deste estudo sugerem que a maternidade ainda faz parte dos seus múltiplos projetos de vida, tenham elas filhos ou não. Apesar disso, ter um filho requer uma reorganização dos projetos de vida voltados tanto para a ampliação do investimento em capital humano como para a conquista de uma carreira profissional. Ademais, como um exercício de aprendizado social, a maternidade parece ser um evento mais fácil de justificar do que sua ausência, mesmo entre mulheres de maior nível educacional. Nesse sentido, para muitas pessoas a maternidade equivale a um atestado de completude e normalidade, já que se encaixa no que é socialmente cobrado das mulheres (MANSUR, 2003). Esse fato demanda uma reflexão mais profunda sobre a relação entre o acesso à educação superior e a transformação de ideais e expectativas relativos à maternidade. Ao mesmo tempo que se colocam incentivos e cobranças para que as mulheres conquistem níveis mais elevados de escolaridade e sigam uma carreira profissional, ainda existem expectativas de que elas cumpram papéis sociais tradicionalmente estabelecidos, dentre eles o da maternidade.

Os resultados desse estudo sugerem que a decisão das mulheres entrevistadas acerca da maternidade não é isenta de dúvidas e se encontra dentro do que Velho (2003) denomina como campo de possibilidades. Ou seja, as decisões acerca da maternidade estão inseridas em um espaço e em um período de tempo em que acontece a interação entre os indivíduos, em que eles estabelecem suas redes de relações e precisam lidar com processos de negociação e escolhas, que nem sempre acontecem de maneira consciente. As escolhas são práticas, portanto, que se reafirmam no decorrer da vida e acontecem em função de eventos circunstanciais. Não se trata de apenas uma escolha, mas sim de um conjunto de escolhas (MANSUR, 2003).

As falas sugerem que as entrevistadas valorizam o acesso à educação superior, mas também desejam outras coisas para suas vidas, inclusive a maternidade. Esta é vista como parte de um projeto que, embora traçado em conjunto com o companheiro, sofre pressões por parte de múltiplas instituições em que estão inseridas, incluindo familiares, amigos e círculos religiosos. 0 adiamento desse projeto parece ser a estratégia utilizada para que outros projetos, também considerados relevantes e mais difíceis de serem realizados, possam ser concretizados depois de se ter um filho. Os resultados também sugerem a existência de um diferencial qualitativo dentro do grupo de mulheres investigado. Ao contrário do que se esperava, para algumas entrevistadas estar concluindo ou já ter o ensino superior parece não ter feito diferença para as expectativas que já possuíam para suas vidas, inclusive em termos de planejamento reprodutivo. Apesar das inúmeras transformações sociais, econômicas, culturais e demográficas que marcam o contexto brasileiro, os resultados observados nesse estudo revelam que a maternidade ainda tem um lugar de destaque na vida das entrevistadas.

As reflexões feitas nesse estudo são apenas o começo de uma história que ainda precisa ser investigada com maior profundidade. Os resultados encontrados trouxeram algumas inquietações sobre o significado, não somente da expansão do ensino superior sobre o desejo pela maternidade, mas também do papel da família no projeto reprodutivo. 
Ademais, o papel da própria mulher como sujeito transformador do comportamento, ao desejar não reproduzir padrões, convenções e atos tradicionais, usualmente norteadores de suas ações e decisões nos relacionamentos (GIDDENS, 1990), é uma realidade que emerge como elemento transformador da relação produção/reprodução e merece um destaque particular nos estudos reprodutivos. Como indicam muitas falas, ela é uma parte importante na construção do desejo por filhos. É inevitável não pensar se em um contexto de diversificação dos grupos religiosos, com notável aumento daqueles de cunho mais conservador, a expansão da educação superior continuará exercendo o mesmo papel de outrora nos níveis de fecundidade. Essas inquietações apontam para a necessidade de continuidade dos estudos já iniciados neste e em outros trabalhos dedicados a conhecer melhor a motivação para a maternidade entre mulheres com características distintas.

\section{Referências}

ADSERÀ, A. Fertility, feminism, and faith: the influence of secularism and economic conditions. In: KAUFMANN, E.; WILCOX, W. B. (ed.). Whither the child? Causes and consequences of low fertility. Boulder, CO: Paradigm, 2015. p. 1-28.

AGRILLO, C.; NELINI; C. Childfree by choice: a review. Journal of Cultural Geography, v. 25, n. 3, p. 347-363, 2008. Disponivel em: http://dx.doi.org/10.1080/08873630802476292. Acesso em: set. 2018.

ALVES, de C. A.; WONG, L. L. R.; MIRANDA-RIBEIRO, P. Discrepant fertility in Brazil. Revista Latinoamericana de Población, v. 10, n. 18, p. 83-105, 2016. Disponível em: https://doi. org/10.31406/relap2016.v10.i1.n18.4

ALVES, J. E. D.; CAVENAGHI, S. M. Timing of childbearing in below replacement fertility regimes: how and why Brazil is different. In: XXVI IUSSP INTERNATIONAL POPULATION CONFERENCE. Proceedings [...]. Marrakesh, Marrocos, 27 de setembro a 2 de outubro de 2009. Disponível em: https://iussp2009.princeton.edu/papers/92527. Acesso em: dez. 2018.

ALVES, J. E. D.; CAVENAGHI, S. M.; BARROS, L. F. W. A família Dinc no Brasil: algumas características sócio-demográficas. Rio de Janeiro: IBGE. Escola Nacional de Ciências Estatísticas, 2010. (Textos para Discussão, 30).

ARAUJO, C.; PICANÇO, F.; CANO, I.; VEIGA, A. Evolução das percepções de gênero, trabalho e família no Brasil: 2003-2016. In: ARAUJO, C.; GAMA, A.; PICANÇO, F.; CANO, I. Gênero, família e trabalho no Brasil do século XXI - mudanças e permanências. 1. ed. Rio de Janeiro: Gramma, 2018.

ATTRIDE-STIRLING, J. Thematic networks: an analytic tool for qualitative research. Qualitative Research, v. 1, n. 3, p. 385-405, 2001.

AZEVEDO, R. A. de. "Amo meu filho, mas odeio ser mãe". Reflexões sobre a ambivalência na maternidade contemporânea. 2017. 33f. Monografia (Curso de Especialização em Psicologia Ênfase em Infância e Família: Avaliação, Prevenção e Intervenção) - Universidade Federal do Rio Grande do Sul (UFRGS), Porto Alegre, 2017. Disponivel em: https://www.lume.ufrgs.br/bitstream/ handle/10183/163940/001025591.pdf?sequence=1\&isAllowed=y. Acesso em: jul. 2020.

BADINTER, E. Um amor conquistador: o mito do amor materno. Rio de Janeiro: Nova Fronteira, 1985.

BARRO, R. J.; BECKER, G. S. Fertility choice in a model of economic growth. Econometrica: Journal of the Econometric Society, v. 57, n. 2, p. 481-501, 1989. 
BASU, A. M. Why does education lead to lower fertility? A critical review of some of the possibilities. World Development, v. 30, n. 10, p. 1779-1790, 2002. Disponivel em: https:// reader.elsevier.com/reader/sd/pii/S0305750X02000724?token=28B060F47C4F866E473FA 63DD1BA858C7C521063A721DED3248601B89ED32DBD70EC6ED0D791B47CE641278C974DC 3A9. Acesso em jun. 2019.

BECKER, G. S. Fertility and the economy. Journal of Population Economics, v. 5, n. 3, p. 185-201, 1992.

BELTRÃO, K. I.; ALVES, J. E. D. A reversão do hiato de gênero na educação brasileira no século XX. Cadernos de Pesquisa, v. 39, n. 136, p. 125-156, jan./abr. 2009.

BERNARDI, D.; FÉRES-CARNEIRO, T.; MAGALHÃES, A. S. Entre o desejo e a decisão: a escolha por ter filhos na atualidade. Contextos Clínicos, v. 11, n. 2, p. 161-173, maio/ago. 2018.

BERQUÓ, E.; CAVENAGHI, S. Fecundidade em declínio: breve nota sobre a redução no número médio de filhos por mulher no Brasil. Novos Estudos, São Paulo, n. 74, p. 11-15, mar. 2006. Disponivel em: http://www.scielo.br/scielo.php?script=sci_arttext\&pid=S010133002006000100001\&lng=en\&nrm=iso. Acesso em: set. 2018.

BERQUO, E.; CAVENAGHI, S. M. Notas sobre os diferenciais educacionais e econômicos da fecundidade no Brasil. Revista Brasileira de Estudos de População, São Paulo, v. 31, n. 2, p. 471-482, jul./dez. 2014 . Disponível em: http://www.scielo.br/scielo.php?script=sci_ arttext\&pid=S0102-30982014000200012\&lng=en\&nrm=iso. Acesso em: jul. 2019.

BERQUÓ, E.; GARCIA, S. Algumas considerações sobre a reprodução tardia no Brasil. In: TURRA, C. M.; CUNHA, J. M. P. da (org.). População e desenvolvimento em debate: contribuições da Associação Brasileira de Estudos Populacionais. Belo Horizonte: Abep, 2012. p. 135-140. (Demografia em Debate, v. 4).

BLACKBURN, K.; CIPRIANI, G. P. Intergenerational transfers and demographic transition. Journal of Development Economics, v. 78, n. 1, p. 191-214, 2005.

BORGES, D. Em nome pai, da mãe e do "Espírito Santo": arranjos familiares e religião do Brasil cotemporâneo. In: ARAUJO, C.; GAMA, A.; PICANÇO, F.; CANO, I. Gênero, família e trabalho no Brasil do século XXI - mudanças e permanências. 1. ed. Rio de Janeiro: Gramma, 2018.

CALDWELL, J. C. On net intergenerational wealth flows: an update. Population and Development Review, v. 31, n. 4, p. 721-740, 2005.

CAMARANO, A.; ARAÚJO, H. E.; CARNEIRO, I. G. Tendências da fecundidade brasileira no século XX: uma visão regional. In: GIFFIN, K.; COSTA, S. H. (org.). Questões de saúde reprodutiva. Rio de Janeiro: Editora Fiocruz, 1999. p. 95-111.

CARVALHO, A. A.; VERONA, A. P. de A. Religião e fecundidade: uma análise do nível e padrão de fecundidade segundo grupos religiosos no Brasil em 2006. Revista de Estudos de Teologia e Ciências da Religião, v. 12, p. 1086-1113, 2014. Disponível em: http://periodicos.pucminas.br/ index.php/horizonte/article/view/P.2175-5841.2014v12n36p1086/7519. Acesso em: set. 2018.

COUTINHO, R. Z. Uma agenda inacabada: monitorando os avanços e desafios dos direitos reprodutivos. Revista Brasileira de Estudos de População, v. 33, n. 1, p. 207-2014, 2016.

ESTEVE, A.; FLOREZ-PAREDES, E. The stability paradox: why expansion of women's education has not delayed early union formation or childbearing in Latin America. Studies in Family Planning, v. 49, n. 2, p. 127-142, 2018. Disponível em: https://onlinelibrary.wiley.com/doi/full/10.1111/ sifp.12055. Acesso em: out. 2019.

FJP - Fundação João Pinheiro. Atlas do Desenvolvimento Humano no Brasil. Belo Horizonte: Fundação João Pinheiro, 2013. Disponível em: http://atlasbrasil.org.br/2013/pt/perfil_m/ governador-valadares_mg. Acesso em: dez. 2018. 
FUJIWARA, J. C. A. M. Mulheres sem filhos no Brasil: uma análise de características socioeconômicas e demográficas, razões e repercussões. 2018. 194f. Tese (Doutorado em Demografia) - Instituto de Filosofia e Ciências Humanas, Universidade Estadual de Campinas (Unicamp), Campinas, 2018.

GAMA, A.; SORJ, B.; ROMERO, K.; VEIGA, A. Tensões entre trabalho e família - recomposições na divisão sexual do trabalho. In: ARAÚJO, C.; GAMA, A.; PICANÇO, F.; CANO, I. (org.). Gênero, família e trabalho no Brasil do século XXI - mudanças e permanências. 1. ed. Rio de Janeiro: Gramma, 2018. p. 83-113.

GIDDENS, A. The consequences of modernity. Stanford: Stanford University Press, 1990.

GIDDENS, A. A transformação da intimidade: sexualidade, amor e erotismo nas sociedades modernas. São Paulo: Unesp, 1993.

GUEDES, M. de C. A presença feminina nos cursos universitários e nas pós-graduações: desconstruindo a ideia da universidade como espaço masculino. História, Ciências, Saúde-Manguinhos, v. 15, suplemento, p. 117-132, jun. 2008. Disponível em: http://www.scielo.br/ scielo.php?script=sci_arttext\&pid=S0104-59702008000500006. Acesso em: set. 2018.

GUEDES, M. de C. Escolaridade e gênero: percepções mais igualitárias? In: ARAÚJO, C.; GAMA, A.; PICANÇO, F.; CANO, I. (org.). Gênero, família e trabalho no Brasil do século XXI - mudanças e permanências. 1. ed. Rio de Janeiro: Gramma, 2018. p. 115-128.

GUIGINSKI, J. T.; WAJNMAN, S. A penalidade pela maternidade: participação e qualidade da inserção das mulheres com filhos no mercado de trabalho. Revista Brasileira de Estudos de População, v. 36, p. 1-26, e0090, 2019.

GUIMARÃES, F. C. M. Caleidoscopicamente mulher: dilemas e desafios contemporâneos. Dissertação. 2010. 146f. (Mestrado em Psicologia) - Departamento de Psicologia Clínica do Instituto de Psicologia da Universidade de Brasília, Brasília, 2010.

HAMMETT, D.; TWYMAN, C.; GRAHAN, M. Research and fieldwork in development. New York: Routledge, 2015.

IBGE - Instituto Brasileiro de Geografia e Estatística. Síntese de indicadores sociais: uma análise das condições de vida da população brasileira: 2017. Rio de Janeiro: Coordenação de População e Indicadores Sociais, 2017. Disponível em: https://biblioteca.ibge.gov.br/visualizacao/livros/ liv101459.pdf. Acesso em: dez. 2018.

JORGENSEN, N.; BARBIERI, A. F.; GUEDES, G. R.; ZAPATA, G. International migration and household living arrangements among transnational families in Brazil. Journal of Ethnic and Migration Studies, 2020 (no prelo).

KOHLER, H. Do children bring happiness and purpose in life? In: KAUFMANN, E.; WILCOX, W. B. Whither the child? Causes and consequences of low fertility. New York: Routledge, 2016. cap. 3.

LANEY, E. K.; HALL, M. E. L.; ANDERSON, T. L.; WILLINGHAM, M. M. Becoming a mother: the influence of motherhood on women's identity development. Identity: an International Journal of Theory and Research, v. 15, p. 126-145, 2015.

LEOCÁDIO, V. A. Childlessness no Brasil: a contribuição das mudanças sociodemográficas para a tendência de zero filho. 2018. Dissertação (Mestrado em Demografia) - Cedeplar/Universidade Federal de Minas Gerais, Belo Horizonte, 2018.

LESTHAEGHE, R. The second demographic transition: a concise overview of its development. PNAS, v. 111, n. 51, p. 18112-18115, Dec. 2014. Disponivel em: https://www.pnas.org/content/111/51/18112/ tab-figures-data. Acesso em: out. 2018. 
LESTHAEGHE, R.; VAN DE KAA, D. Twee demografische transities? [Two demographic transitions?]. In: LESTHAEGHE, R.; VAN DE KAA, D. (ed.). Bevolking: groei en krimp (Mens en Maatschappij). Deventer, The Netherlands: Dutch, 1986. p. 9-24.

LESTHAEGHE, R.; SURKYN, J. Cultural dynamics and economic theories of fertility change. Population and Development Review, v. 14, n. 1, p. 1-45, 1988.

MA, X.; PIAO, X. Income, intra-household bargaining power and the happiness of Japanese married women. Quality of life in Japan. Singapore: Springer, 2020. p. 77-106.

MACHADO, J. S. de A.; PENNA, C. M. de M.; CALEIRO, R. C. L. Cinderela de sapatinho quebrado: maternidade, não maternidade e maternagem nas histórias contadas pelas mulheres. Saúde em Debate, v. 43, n. 123, p. 1120-1131, out./dez. 2019. Disponivel em: https://doi.org/10.1590/01031104201912311. Acesso em: 26 jul. 2020.

MANSUR, L. H. B. Experiências de mulheres sem filhos: a mulher singular no plural. Psicologia: ciência e profissão, v. 23, n. 4, p. 2-11, 2003.

MARTELETO, L.; GUEDES, G. R.; WEITZMAN, A.; COUTINHO, R. Z. Life births and fertility amidst the zika epidemic in Brazil. Demography, v. 57, p. 843-872, 2020.

MCQUILLAN, J.; GREIL, A. L.; SCHEFFLER, K. M.; TICHENOR, V. The importance of motherhood among women in the contemporary United States. Gender \& Society: official publication of Sociologists for Women in Society, v. 22, n. 4, p. 477-496, 2008.

MIKUCKA, M.; RIZZI, E. The parenthood and happiness link: testing predictions from five theories. European Journal of Population, v. 36, n. 1, p. 1-25, 2019.

MIRANDA-RIBEIRO, P.; POTTER, J. E. Sobre "se perder", "vacilar" e não "encontrar o homem certo": mudanças ideacionais, instituições e a fecundidade abaixo do nível de reposição. Revista Brasileira de Estudos de População, São Paulo, v. 27, n. 1, p. 227-231, jan./jun. 2010. Disponível em: https://www.rebep.org.br/revista/issue/view/46. Acesso em: set. 2018.

MIRANDA-RIBEIRO, A.; GARCIA, R. A.; FARIA, T. C. de A. B. Baixa fecundidade e adiamento do primeiro filho no Brasil. Revista Brasileira de Estudos de População, v. 36, p. 1-18, 2019.

MORGAN, S. P.; KING; R. B. Three reasons why demographers should pay attention to evolutionary theories and behaviour genetics in the analysis of contemporary fertility. European Journal of Population / Revue Européenne de Démographie, v. 17, n. 1, p. 31-35, 2001.

MYRSKYLÄ, M.; MARGOLIS, R. Happiness: before and after the kids. Demography, v. 51, n. 5 , p. 1843-1866, 2014.

ODENWELLER, K. G.; RITTENOUR, C. E. Stereotypes of stay-at-home and working mothers. Southern Communication Journal, v. 82, n. 2, p.57-72, 2017. DOI: https://doi.org/10.1080/1041794X.2017.1287214. Acesso em: jul. 2020.

RIOS-NETO, E. L. G.; GUIMARÃES; R. R. de M. The educational gradient of low fertility in Latin America. In: ANNUAL MEETING OF POPULATION ASSOCIATION OFAMERICA. Proceedings [...]. Boston, 2014.

ROCHA-COUTINHO, M. L. Variações sobre um antigo tema: a maternidade para as mulheres. In: KUHN, J. Família e casal: efeitos da contemporaneidade. Rio de Janeiro: PUC, 2005. p. 122-137.

SCAVONE, L. Motherhood: transformation in the family and in gender relations. Interface Comunicação, Saúde, Educação, v. 5, n. 8, p. 47-60, 2001. Disponível em: https://www.scielosp. org/pdf/icse/2001.v5n8/47-59/pt. Acesso em: dez. 2018.

TRINDADE, Z. A.; COUTINHO, S. M. S.; CORTEZ; M. B. Ainda é proibido não ser mãe? A não maternidade tratada nas publicações científicas de psicologia. In: ZANELLO, V.; PORTO, M. (org.). Aborto e (não) desejo de maternidade(s): questões para a psicologia. Brasília: Conselho Federal de Psicologia, 2016. 
VAN DE KAA, D. J. Europe's second demographic transition. Population Bulletin, v. 42, n. 1, p. 59, março 1987.

VELHO, G. Projeto e metamorfose: antropologia das sociedades complexas. 3. ed. Rio de Janeiro: Jorge Zahar, 2003.

VIEIRA, J. M. Diferenciais na fecundidade brasileira segundo a natureza da união: algumas reflexões sobre decisões reprodutivas e a prática de morar junto. Campinas, SP: Núcleo de Estudos de População “Elza Berquó” / Unicamp, 2016. (Textos Nepo, 76).

VISINTIN, C. N.; AIELLO-VAISBGERG, T. M. J. Motherhood and social suffering in Brazilian mommy blogs. Psicologia: Teoria e Prática, v. 19, n. 2, p. 108-116, maio/ago. 2017. Disponível em: http:// editorarevistas.mackenzie.br/index.php/ptp/article/view/10634. Acesso em: jul. 2020.

WILLIS, R. J. The direction of intergenerational transfers and demographic transition: the Caldwell hypothesis reexamined. Population and Development Review, v. 8, suppl., p. 207-234, 1982.

\title{
Agradecimentos
}

Raquel Zanatta Coutinho agradece o suporte da Universidade Federal de Minas Gerais, por meio do Edital 11/2017 (ADRC - Programa Institucional de Auxílio à Pesquisa de Docentes Recém-Contratados ou Recém-Doutorados da UFMG).

Os autores agradecem Bruna Firmino e Sandra Nicoli pelo suporte na condução das entrevistas em profundidade.

\section{Sobre os autores}

Andrea Branco Simão é doutora em Demografia, mestre em Sociologia e graduada em Serviço Social. Assistente social da Universidade Federal de Minas Gerais (UFMG) e pesquisadora e professora voluntária do Centro de Desenvolvimento e Planejamento Regional (Cedeplar/UFMG).

Raquel Zanatta Coutinho é doutora em Sociologia, mestre em Demografia e em Sociologia e graduada em Comunicação Social. Professora adjunta do Departamento de Demografia da Universidade Federal de Minas Gerais (UFMG) e pesquisadora do Centro de Desenvolvimento e Planejamento Regional (Cedeplar/UFMG).

Gilvan Ramalho Guedes é doutor em Demografia, especialista em Finanças e graduado em Economia. Professor adjunto do Departamento de Demografia da Universidade Federal de Minas Gerais (UFMG) e pesquisador do Centro de Desenvolvimento e Planejamento Regional (Cedeplar/UFMG). Coordenador do Epopea/UFMG e da Sub-rede Cidade e Urbanização da Rede Clima.

\section{Endereço para correspondência}

\author{
Andrea Branco Simão \\ Departamento de Demografia - Centro de Desenvolvimento e Planejamento Regional da \\ UFMG - Faculdade de Ciências Econômicas \\ Avenida Presidente Antônio Carlos, 6627, 3ํandar, Pampulha \\ 31270-901 - Belo Horizonte-MG, Brasil \\ Raquel Zanatta Coutinho \\ Departamento de Demografia - Centro de Desenvolvimento e Planejamento Regional da \\ UFMG - Faculdade de Ciências Econômicas
}


Avenida Presidente Antônio Carlos, 6627, 3ํandar, Pampulha

31270-901 - Belo Horizonte-MG, Brasil

Gilvan Ramalho Guedes

Departamento de Demografia - Centro de Desenvolvimento e Planejamento Regional da

UFMG - Faculdade de Ciências Econômicas

Avenida Presidente Antônio Carlos, 6627, 3ํandar, Pampulha

31270-901 - Belo Horizonte-MG, Brasil

\begin{abstract}
Desire for motherhood among women with higher education: conflict, change and permanence
\end{abstract}

This paper analyzes the perceptions and meanings of motherhood for a group of women with high education, married or in consensual union, with no more than one child, residents of a mid-size city. Data come from sixteen semi-structured interviews conducted in 2018 in the municipality of Governador Valadares, MG. Results show that although motherhood is a desired and valued event, the decision is loaded with doubts regarding the difficulties to reconcile raising a child with the desire for freedom and professional growth. Doubts emerge as motherhood continues to have a prominent place in women's lives, even within a rather avant-garde group. Becoming a mother remains a significant event in their lives. Conflicts generated by the simultaneous existence of the desire to be a mother and the new individual projects unveiled to women defies the common perception that links schooling to reproductive intentions.

Keywords: Maternity. Change and permanence. Desire for motherhood. Higher education. Qualitative methods.

\title{
Resumen
}

Deseo de hijos entre mujeres con educación superior: conflictos, cambios y permanencias

Este artículo analiza las percepciones y los significados de la maternidad para un grupo de mujeres con educación superior, casadas o en unión consensual sin hijos o, como máximo, un hijo, residentes de una ciudad de tamaño mediano. Los datos provienen de 16 entrevistas semiestructuradas hechas en Governador Valadares, Minas Gerais, en 2018. Los resultados indican que, aunque la maternidad es un evento deseado y valorado, la decisión de estas mujeres educadas no es indudable en relación con las dificultades para conciliar a un niño con el deseo de libertad y crecimiento profesional porque la maternidad todavía tiene un lugar destacado en la vida de las mujeres y convertirse en madre sigue teniendo un efecto significativo en sus vidas. Los conflictos generados por la concomitancia entre la persistencia del deseo relacionado con la maternidad y la aparición de nuevos proyectos individuales para las mujeres desafían la lógica tradicional que relaciona los proyectos escolares y reproductivos.

Palabras clave: Maternidad. Cambios y permanencias. Deseo de hijos. Educación superior. Métodos cualitativos. 